\title{
EHMTI-0323. Pediatric aspects of venous headache. The indicators of cerebral venous outflow for diagnostics and treatment of children
}

\author{
M Abramova*, S Novoselova, I Stepanova, N Shurupova \\ From 4th European Headache and Migraine Trust International Congress: EHMTIC 2014 \\ Copenhagen, Denmark. 18-21 September 2014
}

Disturbances of cerebral venous hemodynamics define development of child headache. However directed by the diagnosis and subsequent treatment these disturbances are not considered. The absence of diagnostics algorithm and norms of cerebral venous blood flow limits the possibility of timely therapy at children.

\section{Aims}

The studies of headache caused by venous hemodynamics disturbance.

\section{Materials and methods}

600 patients (3-17 years old) who complained of headache have been examined. The data of a blood flow velocity in deep cerebral veins of a brain: in straight venous sinus, vein of Galen, sinuses cavernous defined by Transcranial Color-Coded Duplex.

\section{Results}

Headache caused by cerebral venous dysfunction notes in $47 \%$ of children. The surveyed children had typical headache $(100 \%)$ of holding apart character in occipital and parietal areas after a dream (69\%), after physical activity (14\%) and a long static pose have been revealed (17\%)."Venous" headache at children often can be similar to dizziness. The attacks of headache which are coming to an end with vomiting are revealed at $25 \%$ of children. Children also complained of nasal bleeding as a fountain $(60 \%)$ during a night or day dream (40\%), noise in ears (53\%), ocular pathology refraction(43\%) and expressed vegetative symptoms $(80 \%)$.
We have found clinical signs of the connective tissue dysplasia syndromes at $67 \%$ of children.

Structural cerebral abnormalities (hypoplasia of cerebral venous sinuses) were revealed at $9 \%$ patients of them by MRI .

"Markers" of disturbances in cerebral venous hemodynamics was venous outflow in deep brain veins. The research of parameters of a cerebral hemodynamics was carried out in the conditions of functional rest and after dynamic tests. We suggest modified Valsalva, orthostasis and head-down tilting tests in children .

\section{Conclusion}

Definition of cerebral venous hemodynamic normal indicators in children of different age groups is very important for identification and treatment of headache with cerebral venous disturbances.

No conflict of interest.

Published: 18 September 2014

doi:10.1186/1129-2377-15-S1-B1

Cite this article as: Abramova et al:: EHMTI-0323. Pediatric aspects of venous headache. The indicators of cerebral venous outflow for diagnostics and treatment of children. The Journal of Headache and Pain 2014 15(Suppl 1):B1. 